\title{
SMART GESTRO: A COMPUTER VISION BASED GESTURE CONTROLLED DEVICE
}

\section{R. MOULEESHUWARAPPRABU, T. KALAVATHI DEVI, S. NIVIYADHARSHINI, K.M. SATHISH, T. SUDHARSAN \& M. YASHAR ARAFATH}

Research Scholar, Department of Electronics and Instrumentation Engineering, Kongu Engineering College,

Erode, Tamil Nadu, India

\begin{abstract}
Hand signal is a creative system for the man-machine interface. When contrasted with standard procedures, the hand signal method has the benefit of being easy to utilize. By utilizing this strategy, the customary methods for utilizing a console and mouse are altered because of one will at that point move with the pc with hand motions. Right now, modules of hand signal predominant method are utilized. The essential one, ultrasonic detecting component is utilized to arrange the hand development continuously. The separation of two hands is estimated by utilizing sound waves. The most arrangement of this methodology is to expand the speed of communication with a PC, utilizing general equipment, coordinated sheets and moderate locators like a ultrasonic sensor. Another new methodology for prevailing mouse development is done by utilizing a period camera. Crude methodologies include dynamic mouse components like mixing it up of catches or changing the situation of the stylus pen. Be that as it may, during this strategy, PC vision innovation is utilized. Picture division and signal acknowledgment are acclimated track the client's hand bearing shading tops in two measurements. The hand signal is a basic and agreeable strategies for correspondence to coordinate mouse tasks (left and right-clicking, twofold tapping, and investigating exercises).

KEYWORDS: Man-Machine Interface, Human Gesture Technique, Ultrasonic Sensor, PC Vision
\end{abstract}

Received: Jun 06, 2020; Accepted: Jun 26, 2020; Published: Jun 30, 2020; Paper Id.: IJMPERDJUN2020146

\section{INTRODUCTION}

Vision and motion are the indispensable methodologies for correspondence between individuals when all is said in done basically inside indistinguishable methods from console and mouse play an occupation in collaborating with the pc. Quantities of powerful strategies are available for association with the pc and one among them is hand motion procedure. During this venture, 2 viable methods are utilized. Inside the underlying procedure, the hand motion is utilized as partner input that replaces the common sense of mouse and console crosscut keys. The hand signal is a pretty and faster strategy. Ultrasonic sensors are utilized for determinant client hand separation. By utilizing hand motion clients will speak with PCs essentially and there is no might want for any physical relationship among client and framework. [5]

As building keeps on building up every minute, people have littler electronic gadgets and need to utilize them universally. Utilizing human registering association (HCI) a chose vision-based signal and visual discernment are made. Easy interfaces exist effectively, similar to smaller than expected console, envelope console, and inserted console. Be that as it may, though move these interfaces couldn't be utilized and wish some amount of territory to utilize. By applying vision innovation and predominant the mouse by regular hand signals, the space required might 
be decreased. During this task, one of a kind methodology that utilizes a video gadget to manage the mouse framework is arranged. This mouse framework will deal with all mouse errands like clicking, double-tapping and looking over. Some picture procedure calculations are acclimated actualize this pc vision system. [4]

Continuous through the intricate examination on the writing it is wanted to build up a framework that controls the real elements of console and mouse by hand signal.

A Hands Gesture System of the executives for an Intelligent seat (2007), presents the fractional winds up in case of a seat constrained by partner instinctive interface, any place the bearings are given by hand signal guidelines.

Xu Zhang, Xiang Chen, Wen-hui Wang (2009), presents a virtual Rubik's Cube game that is constrained by hand motions and it is utilized for assessing the exhibition of the hand signal acknowledgment framework. Strategy for utilizing signal articles for PC control (2009), A technique for controlling PC activities by showing realistic items in a PC domain and entering client contributions to the PC condition through client associations with realistic items.

\section{OBJECTIVES}

- To build a virtual control system that operates human-machine interface without any additional hardware requirements

- To build a user-friendly gesture control system with minimal cost that reaches out to the market with ease.

\section{PROBLEM STATEMENTS}

- The existing framework comprises of trackpad framework and nonexclusive mouse of screen controlling and the non-accessibility of a hand motion framework.

- The remote access of screen utilizing the hand signal is lumbering with the present motion control framework

\section{METHODOLOGY}

This paper introduces a way supported the identification of hand gestures by using detector and camera consequently a specific operation is performed. Some recognition ways of the gestures are planned so actions are recognized using vision and gesture. Groups from two major stream strategies based on action recognition by computer vision techniques are explained below.

\section{ULTRASONIC TOUCHLESS GESTURE TECHNIQUE (MODULE 1)}

Constant human-PC communication utilizing hand signals are utilized for a copious common sense like video the executives, music player, gaming, overwhelming the elements of a PDF peruse, and so forth. A signal controller goal consistently needs a physical gadget that follows and recognizes the visual correspondence or developments, so the PC will explain them. By utilizing an ultrasonic locator, the information is taken care of to the framework as far as the zone between the framework and furthermore the sensors. Predictable with the space of hand, a particular activity is performed.

Motion control depends on explicit hand positions and furthermore the yields got from ultrasonic sensors. To process the information, a smaller scale controller is significant. Thus, the Arduino UNO board is utilized. Through the USB affiliation, the microcontroller moves the handled and determined separation incentive to the locator. The data that is transported by the locator is prepared inside the product framework in PC any place all the estimations are performed and 
furthermore the information is coordinated with the predefined conditions (signal goals). During this model, two ultrasonic sensors are familiar with discover hand positions and are associated with the Arduino board. Since it is comprehended, the ultrasonic finder ceaselessly produces sound and it gets reflected back from the client's hand. The region between the sounds is transported and recognition of repeat back ultrasonic waves is determined by the miniaturized scale controller. [3]

This model has the ensuing equipment segments; these are two ultrasonic detecting parts (HCSR-04) and furthermore the Arduino UNO board. In figure four shows the circuit graph of the model. The framework module incorporates the Arduino IDE and python graphical interface. It matches motions with predefined conditions and prints on the python yield shell as appeared inside the figure: i. Collaboration among python and Arduino program occurs by composing the Arduino port differ into python program. Table No.1 shows the mapping between the hand motions and yield made by the framework. The significant piece of this task is to write down a program for Arduino such it changes over the separations estimated by everything sensors into the satisfactory orders for prevailing limited activities.

\section{Implementation Builds}

An idea utilized here is to live the region of the hand in front of each ultrasonic identifier during this venture.

The hand motions before the ultrasonic sensors are marked all together that they can perform inside and out totally various errands on PC are referenced underneath.

- Switch to Next Tab in the partner degree program

- Look Down in a site page

- Look Upon a site page

- Switch between several Tasks (like MS Word and VLC Player)

- $\quad$ Play or Pause the Video in VLC Player

- Increasing the Volume

- Decreasing the Volume

Following are the 5 specific hand signs or exercises that it is adjusted for show reason.

- Signal 1: Place the turn before the right ultrasonic identifier far off (between 15CM to $65 \mathrm{CM}$ ) for a little period and move the football play from the contraption. These movements will Look Down the net Page or Decreasing the sum.

- Signal 2: Place the hand before the most ideal ultrasonic discoverer a way off (between $15 \mathrm{CM}$ to $65 \mathrm{CM}$ ) for a little period and move the hand towards the locator. This movement will look upon the net Page or Increasing the sum.

- Signal 3: Swing the hand before the benefit ultrasonic discoverer. This movement will move to consecutive Tab.

- Signal 4: Swing the hand before the Left ultrasonic marker. This sign will move to the Previous Tab or Play/Pause the Video. 
- Signal 5: Swing the hand over everything about locators (Left sensor first). This action will switch between tasks.
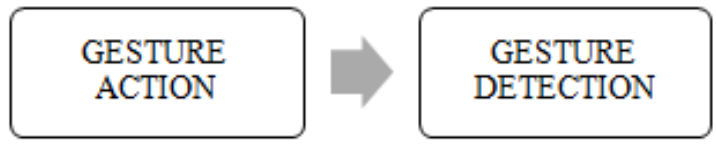
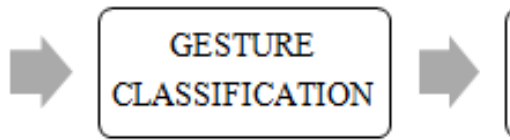

GESTURE CONTROL

Figure 1: Ultrasonic Gesture Control.

\section{Circuit Diagram}

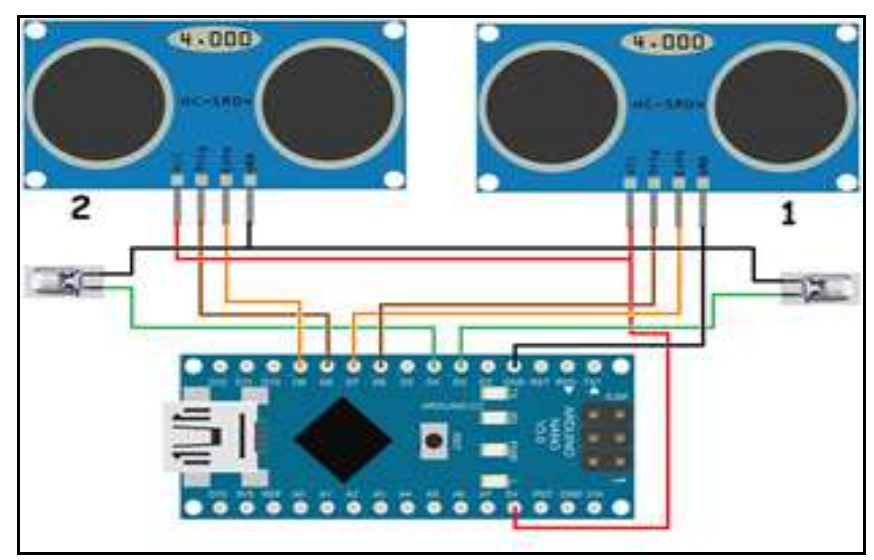

Figure 2: Circuit Diagram of Ultrasonic Touchless Gesture.

\section{Implementation}

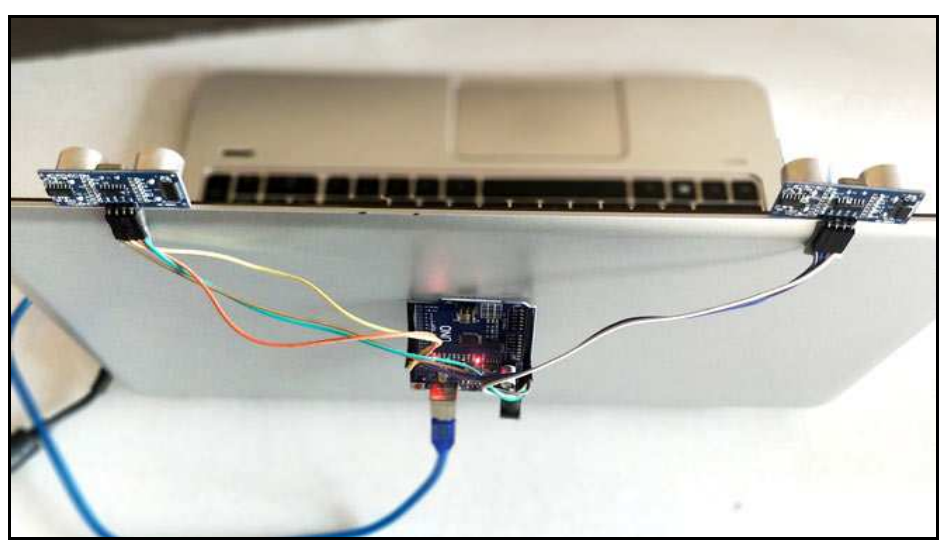

Figure 3: Circuit Connection of Ultrasonic Touchless Gesture.

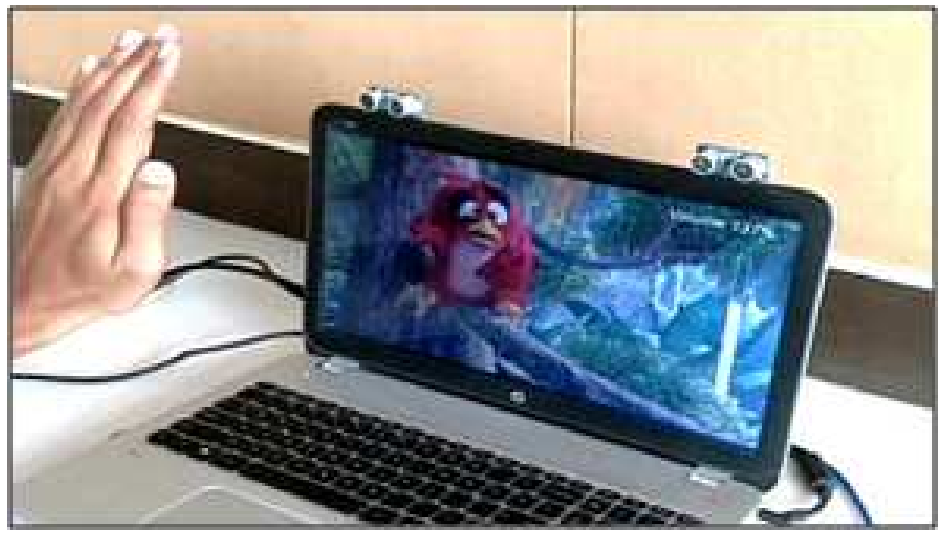

Figure 4: Real Time Application. 


\section{VIRTUAL CURSOR CONTROL (MODULE 2)}

The anticipated framework might be a time span video processor that is an ongoing application framework. this may supplant one in everything about routinely utilized data gadgets for example mouse, a stylus pen and different manual wired gadgets subsequently just by giving the hand signals the client can't move normally with their versatile PC. The major outline of the anticipated framework is as appeared underneath inside the figure. Eventually in light of the fact that the article with the nominative estimation is recognized by the camera, it starts getting the video and takes out these photographs and starts the procedure. The readied picture is given as a commitment to successive sections of method where it starts distinguishing the palm following the concentrations and edges. Every single isolated option is used for the additional system like acknowledgment hand flags and dealing with respect to it. The stream diagram of the orchestrated structure has showed up for the one packaging that is gotten. The framework could likewise be a timeframe framework that the stream diagram may be a ceaseless strategy for each and each edge that will be caught by a camera. [2]

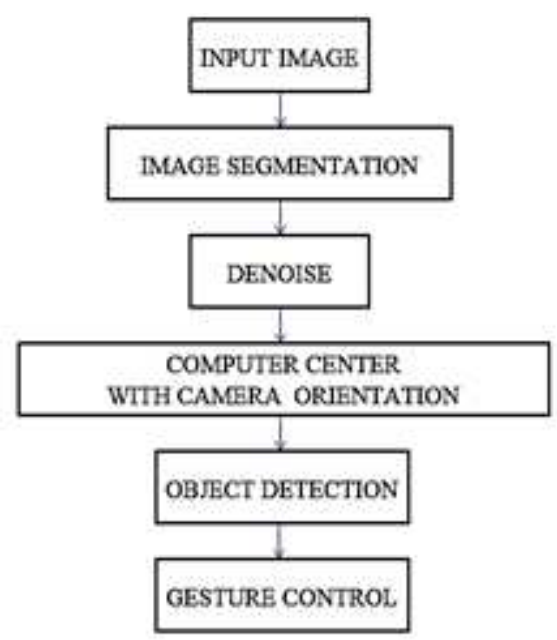

Figure 5: Virtual Gesture Control.

\section{Background and Scope}

The inspiration of Virtual Mouse is previously mentioned that the Virtual Mouse can by and by supplant the standard physical mouse sooner rather than later, any place the client's zone unit meaning enthusiasm towards innovation which will be open even remotely while not access of any outside gadgets. This may expand the extent of comfort and cost-adequacy.

Financially Savvy: A top-notch physical mouse will have a variety of its worth retribution on its alternatives installed on the grounds that the virtual mouse needs solely a web camera, the investments spent on a physical mouse is unnoticed and one web camera is adequate for the users to associate with automatic data processing system, whereas the portable systems like a laptop computer have associate degree in-built web camera that just wants the virtual mouse software package for enabling the service. [1]

Helpful: The clients need a real physical mouse to speak with a PC, which needs an unequivocal piece of a territory to work; in any case, it's not to determine the link's length limitations it endures. In any case, the virtual mouse makes it advantageous as there's a necessity of exclusively a web camera that grants picture catching of client's hand position, the 
shading paper identification thus as to consummately decide the situation of the pointers that the client need it to be by moving fingers, along these lines killing the prerequisite to physically move the physical mouse.

\section{Scope}

To supplant the physical mouse, the virtual mouse is after a short time presented; to improve comfort which can have the option to precisely convey and manage the PC framework. To technique those highlights, the module created ought to be sufficiently quick to catch and utilitarian each picture, in order to effectively follow the client's motions and consequently the shading papers utilized on them. Consequently, this module application is helped with the most recent programming bundle coding methods and open-source library alluded to as the Open CV. [6]

The degree of this application takes into consideration different functionalities.

- Evacuates the requirement for getting a physical mouse

- User-pleasing application

- Real-time application

Right when the customer's sign is gotten persistently by the webcam, the application starts planning, where they got picture will be dealt with for division in order to amass which pixels regards equal to the described concealing characteristics. At the point when the methodology of division is done, the general picture will be changed over to a twofold picture where the recognized pixels will have showed up in white and the rest is dim. The circumstance of the white zone in the image will be recorded and sent as the circumstance of the mouse pointer, thus achieves duplicating the mouse pointer without the use of a physical mouse.[10]

\section{Effect and Its Significance}

The virtual mouse application is fit for displacing all the current systems for utilizing a physical PC mouse where manual exercises can be supplanted. It offers a simple method to speak with the PC framework, where each task can be motion performed. Also, this application could coordinate the engine hindered clients by simply demonstrating the right grouping of hues to the webcam. [7]

\section{Novelty Perspectives}

For this framework, there is no requirement for sound to be made so no interference of foundation and commotion. A scope of elements of PCs is regularly worked by a partner ultrasonic gadget. This technique is moreover helpful for people that don't catch practically of an individual framework. This philosophy diminishes the instructing time required. By utilizing this procedure, it is anything but difficult to have cooperation with the pc and there's no obstruction. By using this procedure, the control might be done from a little separation and it would encourage direct work stations in space shows. 


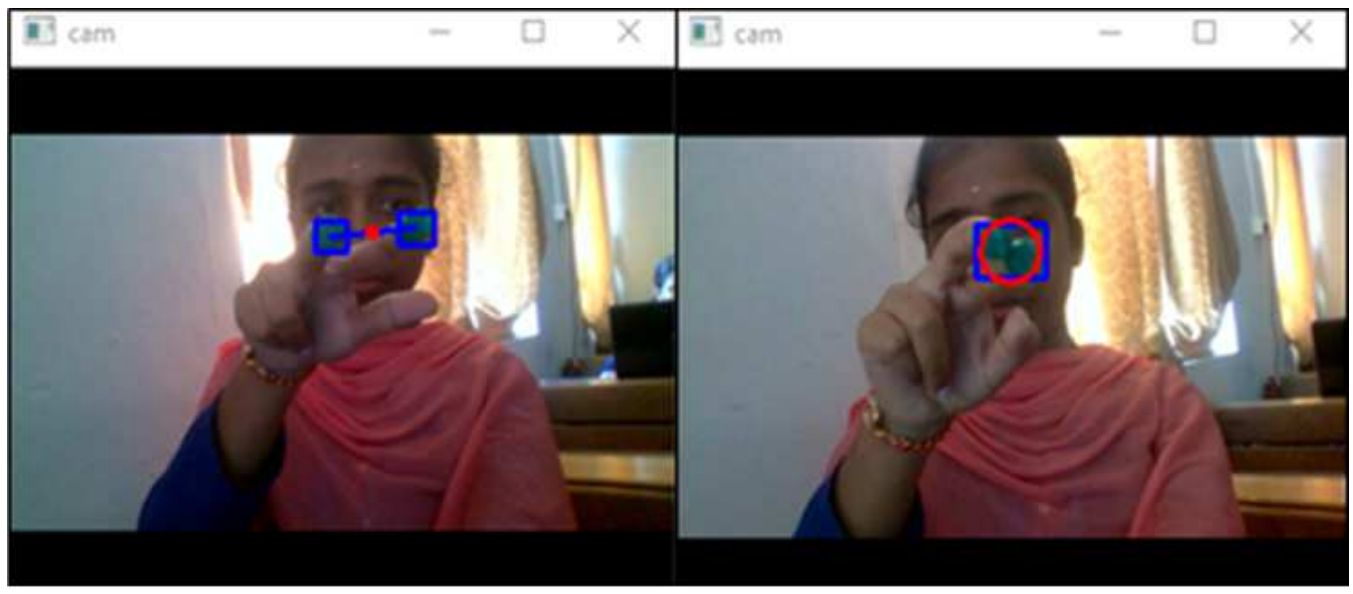

Figure 6: Cursor Point Control.

\section{RESULTS AND DISCUSSION}

The sensor which is utilized right now is extremely less force. The module is created in the minimal effort where right now the sensor is utilized to identify hand signal or separation of hand and as per condition activity is performed on PC. The arrangement that appeared in the article is implementable and helpful for the client. On the opposite side, the virtual signal control framework was done on different conditions, the application perceives hues and separates them effectively in both more splendid and darker situations than typical, yet as far as possible is until the RGB regards stay unaltered by the effect of brightness. Furthermore, it works from a division of pointers changing from $15 \mathrm{~cm}$ to $65 \mathrm{~cm}$ from the particularly lowgoals webcam. It additionally works despite the fact that the webcam isn't on the pivot, it might be tilted to any point, yet the application sets it accurately.

Partition is one of those issues that may impact the results, as the current distinguishing proof area can reinforce up to $1 \mathrm{~m}$ clear, any grandstand of tones that outperform the referenced detachment will be considered as commotion and be filtered off. The display of the program is dependent upon the customers' hardware, as processor speed or objectives delivered from the webcam brings about the introduction load. Right now, the slower the taking care of speed or the higher the objectives, the more drawn out time is required to process a singular edge.

Table 1: Results of Ultrasonic Gesture Control Module and Virtual Cursor Control Module

\begin{tabular}{|l|c|c|c|}
\hline \multicolumn{1}{|c|}{ EVENTS } & $\begin{array}{c}\text { NO. OF INPUT } \\
\text { SAMPLES }\end{array}$ & $\begin{array}{c}\text { NO. OF } \\
\text { RECOGNIZED } \\
\text { SAMPLES }\end{array}$ & $\begin{array}{c}\text { RECOGNITION } \\
\text { RATE }\end{array}$ \\
\hline MODULE: 1 & \multicolumn{2}{|c|}{ ULTRASONIC GESTURE CONTROL MODULE } \\
\hline Right Hand Push In & 130 & 126 & 0.969 \\
\hline Right Hand Pull Out & 130 & 126 & 0.969 \\
\hline Left Hand Push Out & 130 & 127 & 0.976 \\
\hline Left Hand Pull Out & 130 & 127 & 0.976 \\
\hline MODULE: 2 & \multicolumn{2}{|c|}{ VIRTUAL CURSOR CONTROL MODULE } \\
\hline Drag & 130 & 123 & 0.946 \\
\hline Move & 130 & 122 & 0.938 \\
\hline Click & 130 & 122 & 0.938 \\
\hline Increase Speed Of The Cursor & 130 & 128 & 0.984 \\
\hline Decrease Speed Of The Cursor & 130 & 125 & 0.961 \\
\hline
\end{tabular}




\section{CONCLUSION AND FUTURE SCOPE}

A framework to direct the mouse pointer utilizing a time span web camera is created to execute all mouse assignments like left and right-clicking, double-tapping, and looking over. This technique relies upon PC vision calculations and can do all mouse assignments. Be that as it may, it's incredible to ask stable outcomes because of the inconstancy of lighting and skin shades of human races. Most vision calculations have enlightenment issues. From the outcomes, it is normal that on the off chance that the additional vision calculations are extra, at that point this strategy can work more with effectiveness. This framework is likewise helpful in shows and to curtail zone. This article presents one in all the arrangements among changed others, for operational a PC using hand motions. It is one in every one of the most ideal manners by which of cooperation among people and PCs. It is a partner monetary model that would be essentially upheld by Arduino UNO and ultrasonic sensors. The python IDE licenses consistent combination with Arduino UNO along these lines on accomplish the unmistakable procedures and predominant manners by which of building new signal administration arrangements. The hand motion method can't be confined to a bad habit, using the essential activity of a pc it is regularly helpful for clinical applications. The hand motion procedure can function as a partner input system between clinical instruments and in this way the physical structure as arranged. It is frequently utilized for operational each every performs of modified frameworks.

\section{ACKNOWLEDGMENT}

We extend sincere gratitude to Dr. U.S. Raghupathy, M.E, PhD, Head of the Department, Department of Electronics and Instrumentation Engineering, Kongu Engineering College for his ideas and suggestions, that were very useful to make this project a successful one.

\section{REFERENCES}

1. Cost effective hand gesture computer control interface (2016), Gergely Sziládi, Tibor Ujbányi, József Katona.

2. Vision based computer mouse control using hand gestures (2015), Sandeep Thakur, Rajesh Mehra, Buddhi Prakash, International Conference on Soft Computing Techniques and Implementations (ICSCTI).

3. A basic hand gesture control system for PC applications (2001), C.J. Cohen, G. Beach, G. Foulk Proceedings, 30th Applied Imagery Pattern Recognition Workshop (AIPR 2001). Analysis and Understanding of Time Varying Imagery.

4. A system for controlling personal computers by hand gestures using a wireless sensor vice (2014), Kaorumagishi, Lei Jing, Zixue Cheng, IEEE International Symposium on Independent Computing (ISIC).

5. Visual Mouse: SIFT Detection and PCA Recognition (2007), Hailing Zhou, Lijun Xie, Xuliang Fang,International Conference on Computational Intelligence and Security Workshops (CISW 2007).

6. DigitEyes: Vision-Based Hand Tracking for Human-Computer Interaction (1994), James M. Rehg, Takeo Kanade,Proc. of the IEEE Workshop on Motion of Non-Rigid and Articulated Objects.

7. Learning Open CV (2008), Gary Bradski, Adrian Kaehler.

8. A Fast Algorithm for Vision-Based Hand Gesture Recognition for Robot Control (2016), Asanterabi Malima, Erol Ozgur, and Mujdat Cetin.

9. Image Analysis and Mathematical Morphology (1994), J. Serra, Academic Press. 
10. An image processing method for feature extraction of space-occupying lesions (1985), K. Homma and E.-I. Takenaka, Journal of Nuclear Medicine.

11. Kumar, S. Ramesh, et al. "Design and fabrication of autonomous robot for precision agriculture." International Journal of Mechanical and Production Engineering Research and Development (IJMPERD) 8.3 (2018): 385-392.

12. Murmude, P B, and J G Rana. "Intelligent Embedded Control Warning System for Car Reversing." International Journal of Electronics and Communication Engineering (IJECE) 2.3 (2013):133-136

13. Sheikh, Sajid M., Lebone Powder, and Ibo Ngebani. "A Smart Microprocessor-Based Four Way Stop Road Traffic Controller." International Journal of Electrical and Electronics Engineering (IJEEE) 7.4 (2018):9-22

14. Lad, Manisha, VV Shete, and S B Somani. "Soft computing approaches for hand gesture recognition." International Journal of Computer Science Engineering and Information Technology Research (IJCSEITR) 3.4 (2013): 55-58.

15. Singh, Sahib, and Vijay Kumar Banga. "Gesture Control Algorithm for Control of Personal Computers." International Journal of Electronics and Communication Engineering (IJECE) 2.2 (2013):143-152

16. Kumar, P. Dinesh, and B. Rosiline Jeetha. "A Survey on Facial Expression Recognition." International Journal of Computer Science and Engineering (IJCSE) 6.1 (2017):43-50

17. Agarwal, Megha, Kapil Goyal, and Manoj Makhija. "Computer Applications Control by Hand Gesture Recognition." International Journal of Electronics, Communication \& Instrumentation Engineering Research and Development (IJECIERD) 4.5 (2014):37-46 

